\title{
A Study on Microstructure of AA2219 Friction Stir Welded Joint
}

\author{
Ho-Sung Lee ${ }^{1, a *}$ Joon-Tae Yoo ${ }^{1, b}$, Jong-Hoon Yoon ${ }^{1, c}$, and Kyung-Ju Min ${ }^{2, d}$ \\ ${ }^{1}$ Launcher Structure \& Materials Team, Korea Aerospace Research Institute, 169-84 Gwahangno, \\ Yuseong-Gu, Daejeon 34133 Republic of Korea \\ ${ }^{2}$ Aerospace Application \& Materials Research Team, Korea Aerospace Research Institute, \\ 169-84 Gwahangno, Yuseong-Gu, Daejeon 34133 Republic of Korea
}

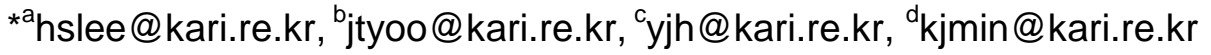

Keywords: Microstructure, AA2219, Friction Stir Welding, Tool, Aerospace, Aluminum Alloy

\begin{abstract}
Friction Stir Welding (FSW) is an environment friendly solid-state joining technology that uses a rotating tool to generate frictional heat and plastic deformation with mixing of the soft material by the pin along the welding line. The advantages are low distortion, lack of traditional defects commonly found in fusion welds and high joint efficiency. The paper focuses on microstructure evolved after welding and the effect of welding process is discussed for aluminum alloy 2219 . This alloy is selected because of high strength and good resistance to stress corrosion cracking at cryogenic temperature. The optimum process condition for FSW is determined with microstructural and mechanical properties. It is shown that the FSW provides higher performance for this alloy than the conventional welding technology.
\end{abstract}

\section{Introduction}

Friction Stir Welding (FSW) process is an environment protective process and does not produce toxic fumes with no consumable filler material involved unlike the conventional fusion welding. In most fusion welding processes, there are problems of possible porosity, hot cracking, solute segregation and precipitation behavior change. In FSW, the probe of the tool is applied to the contact faces of the workpieces and spinned to produce frictional heat in the work piece. This process creates a softened deformed region around the probe and by keeping the tool rotating and moving it along the joint line to be welded. The softened material is stirred and mechanically mixed together by the rotating probe forming a weld without melting $[1,2]$. The rotating shoulder provides additional frictional heat as well as preventing deformed material from being expelled from the weld. One plate where the direction of rotation is the same as that of welding direction is the advancing side (AS), with the other plate designated as being the retreating side (RS). As the temperature increases, the plastically deformed material is extruded from the advancing side to the retraction side of the tool by the applied shear stress. As a solid state joining process, FSW significantly improves the weld properties and has been extensively applied in joining light metals by offering advantages over fusion welding due to the absence of metal melting. Absence of melting in FSW reduces oxidation, residual stress, and other solidification related defects. The resulting FSW joint consists of several zones involving different microstructures and mechanical properties. The microstructure of the typical friction stir weld shows a central stirred zone which is the region that is thermo-mechanically processed zone where the grain size is refined and homogenized, the thermo-mechanically affected zone (TMAZ), close to the stirred zone, where the grain is elongated, and the heat affected zone (HAZ) with the same grain structure of the base material.

Aluminum alloys play major role in the aerospace applications because of high strength, low weight, good formability, corrosion resistance and machinability. Aluminum alloy spontaneously forms an effective and stable oxide on its surface that prevents further oxidation. However, this aluminum oxide easily absorbs moisture from the air and during the welding process hydrogen is soluble in liquid aluminum alloy. As the alloy solidifies, with a rapid cooling rate since the thermal 
conductivity is high, hydrogen in oxide causes porosity in the welds. The variable polarity plasma arc process was developed to break surface oxide films of aluminum alloy by rapid switching the electrode polarity from negative to positive several times per second during welding. The oxide film is broken constantly and the rapid cycle changes result in extremely low levels of porosity. Among all aluminum alloys, aluminum alloy 2219 with strain hardening of solution treated products accelerates the response to artificial aging and provides higher strengths so that it has special applications in missiles and space vehicles with excellent resistance to brittle fracture at cryogenic temperature [3]. The alloy shows relatively good weldability which makes wide application for joining several pieces to fabricate the large structure like a launch vehicle tank [4]. This is due to the presence of $\mathrm{Cu}$ which provides extra eutectic to heal solidification voids in this alloy. It is known that the strength of welded joint from gas tungsten arc welding is about $57 \sim 62 \%$ of the base metal $[5,6]$. The major problems that arise in arc welding of AA2219 are the adverse development of residual stresses and the re-distribution as well as dissolution of the strengthening precipitates in the weld joint [6]. This problem can be reduced by using the solid state welding like FSW.

The present paper reports a microstructural and mechanical study on 2219-T87 friction stir welded plates. Microhardness tests were carried out on different zones. Discussion includes different mechanical properties and the microstructure changes.

\section{Experimental}

The aluminum alloy 2219-T87 was obtained as a sheet with $4.5 \mathrm{~mm}$ thickness from Alcoa. FSW processes have been carried out by using a properly designed clamping fixture to fix the two sheets $(300 \mathrm{~mm} \times 100 \mathrm{~mm})$ with the rolled plate be welded on a milling machine. The image of the tool pin profile is shown in Fig. 1. The shoulder was threaded spiral and the diameter of the shoulder is $16 \mathrm{~mm}$. The pin was threaded conical with $4.26 \mathrm{~mm}$ length. The details of the tool geometry are important and are proprietary. The welding direction was perpendicular to rolling direction. FSW processes were made using tool rotation rates from 600 to $2,000 \mathrm{rpm}$ and tool traveling speeds from 0.8 to $15 \mathrm{~mm} / \mathrm{sec}$ using a tool tilt angle of $3^{\circ}$. Single pass welding procedure was used to fabricate the joints. Since the temperature increase during FSW process directly influences the microstructure of the weld, the temperature distribution around the tool is monitored with Infrared camera (ThermoVision A40M). After welding, all of the specimens were inspected by radiography [7] and the specimens with defects were discarded. The welded joints are sliced along the welded joint for machining of tensile specimens with $57.15 \mathrm{~mm}$ gage length and $12.8 \mathrm{~mm}$ wide. The tensile test was performed at room temperature using a $100 \mathrm{KN}$ MTS 810 machine under crosshead speed of $2.0 \mathrm{~mm} / \mathrm{min}$. For optical microstructure, the specimens were etched with Graff-Sargent solution followed by Keller's solution.
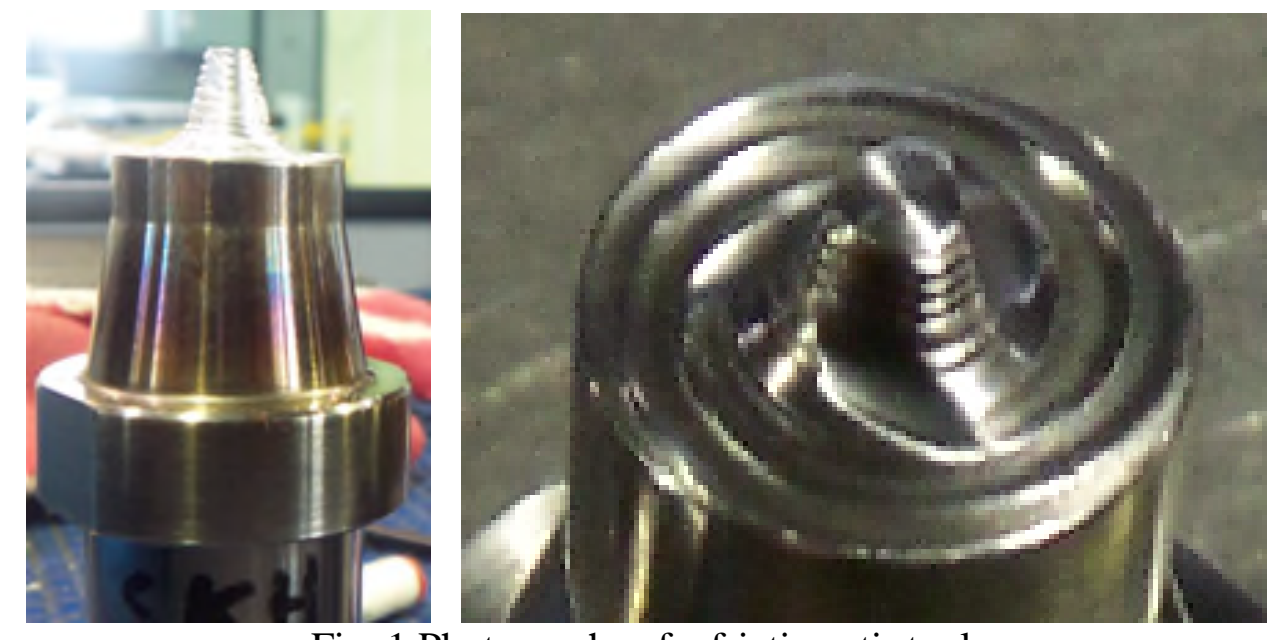

Fig. 1 Photographs of a friction stir tool. 


\section{Results and Discussion}

Fig. 2 shows the result of temperature measurement during FSW. The frictional heat increases the temperature of welded joint and changes the microstructure. General trend is when the rotating rate is relatively low, the higher travelling speed, the lower peak temperature. The rotation rate has a relatively minor effect on the temperature profile at constant travelling speed. This is because the faster travelling speed will induce a lower heat input per unit distance to the weld zone and the rotation rate determines the quality of heat production and degree of plastic deformation [8]. The peak temperature is obtained at $1,000 \mathrm{rpm}$ and $3 \mathrm{~mm} / \mathrm{sec}$. The peak temperature of each process condition was relatively compared each other, but was low comparing to the typical one for aluminum alloy reported in literature [5, 8], and this is due to the different type of measuring method. Direct measurement using thermocouple is preferred.

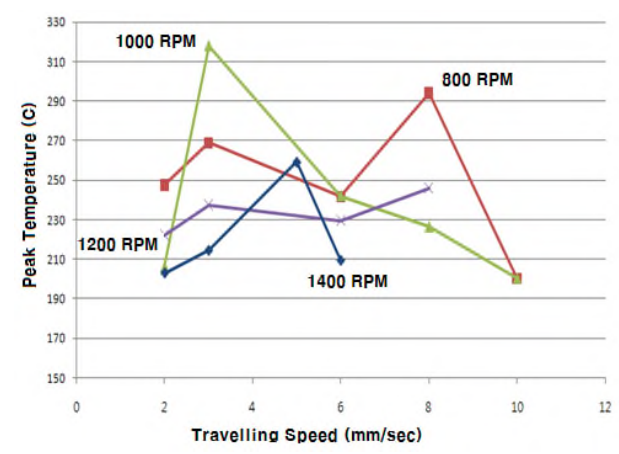

(a)

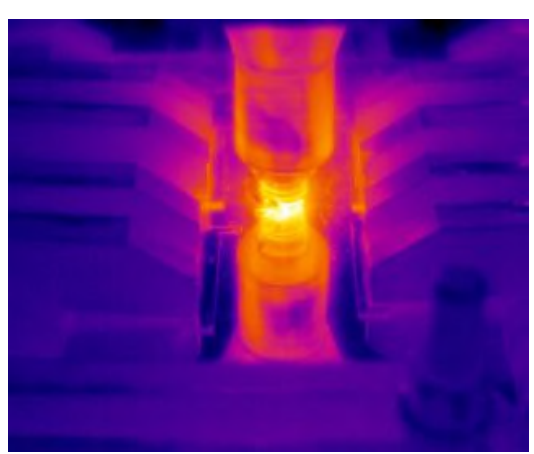

(b)

Fig. 2 Result of (a) peak temperature measurement at different welding conditions, and (b) thermal image during FSW

Fig. 3(a) shows typical cross sectional view of the stirred zone of friction stir welded AA2219 at different process conditions. Other conditions not presented in Fig. 3 (a) were not passed for the radiographic inspection so not included. For the specimen welded in 1,400 rpm and $6 \mathrm{~mm} / \mathrm{sec}$, there are voids in the cross-section which were detected in radiographic inspection as shown in Fig. 3 (b). The voids were on the advancing side of the weld between the stirred zone and the TMAZ. It is due to the fast rotation rate causes anomalous viscoplastic form of the material with lack of accommodation of the material interface between two zones [9]. It is assumed that the forging pressure should be increased in this condition to prevent this type of defects.

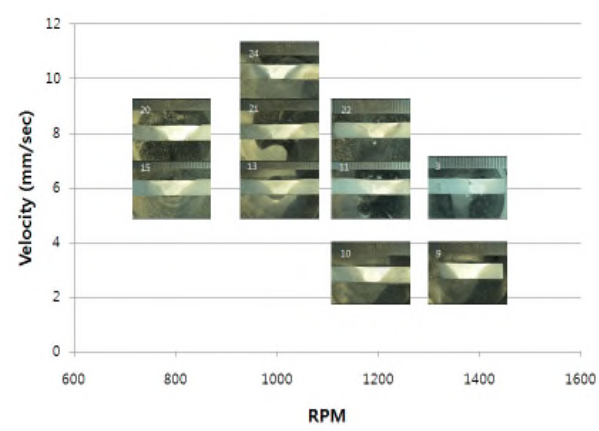

(a)

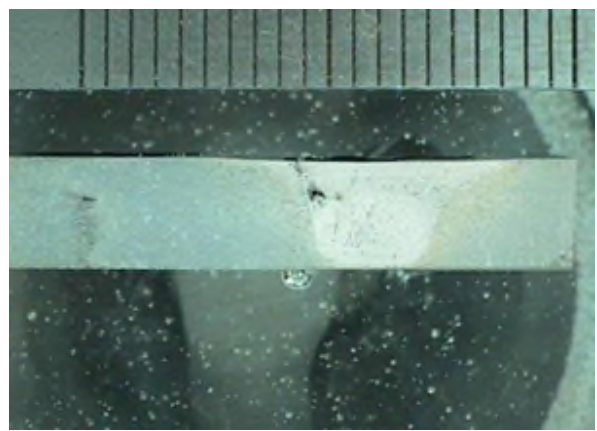

(b)

Fig. 3 Optical macrographs of cross-sectional view (a) for different process conditions and (b) for specimen with defects welded in 1,400 rpm and $6 \mathrm{~mm} / \mathrm{sec}$.

Fig. 4 shows an example of microstructure of the stirred zone of friction stir welded AA2219 at two different process conditions. The effect of travelling speed on the microstructure of the stirred zone is shown and material in the stirred zone experience sufficient deformation and heat input which 
cause the complete dynamic recrystallization. The faster travelling speed, the smaller grain size in the stirred zone.

\begin{tabular}{|c|c|c|c|c|}
\hline & Base Material & HAZ on AS & Stirred Zone & HAZ on RS \\
\hline \multicolumn{5}{|l|}{$1,000 \mathrm{rpm}$} \\
\hline $6 \mathrm{~mm} / \mathrm{sec}$ & & & & \\
\hline $1,000 \mathrm{rpm}$ & & & & \\
\hline $8 \mathrm{~mm} / \mathrm{sec}$ & & & & \\
\hline
\end{tabular}

Fig. 4 Optical micrographs of each region for (a) specimen welded with 1,000 rpm, $6 \mathrm{~mm} / \mathrm{sec}$, and (b) specimen welded with 1,000 rpm and $8 \mathrm{~mm} / \mathrm{sec}$.

Fig. 5 shows effects of welding parameters on mechanical properties. The processes specified with $\mathrm{X}$ indicates the specimen with welding defects. Generally at the rotating ratio of 1,000 RPM, all of the specimens show the efficiency over $70 \%$ without any defects. The maximum efficiency obtained in this study was $72 \%$. The current result is supported with the published work [10] which has been reported at $400 \mathrm{RPM}$ and $180 \mathrm{~mm} / \mathrm{min}$. At higher rotating rate, only specimens welded at low speed were accepted in this alloy. The strength of the specimens welded at 1,000 RPM is relatively insensitive to the travelling speed. After inspecting the failure mode, it is shown that the $70 \%$ of the specimens failed on the retreating side of the interface between stir zone and thermo-mechanical affected zone.

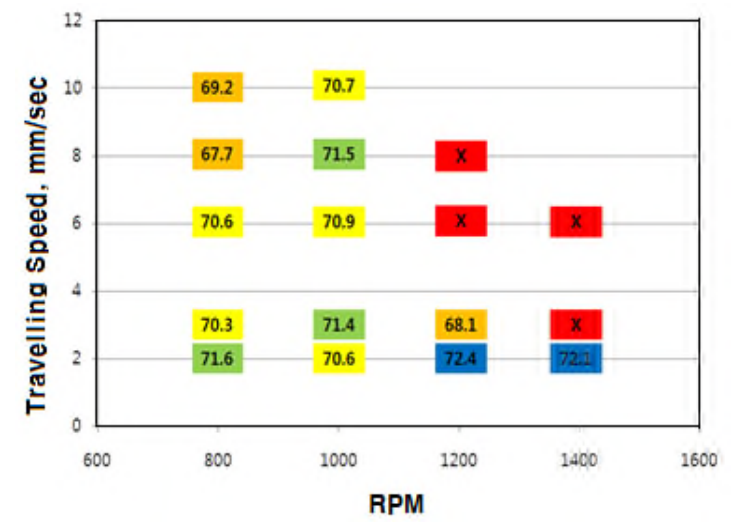

(a)

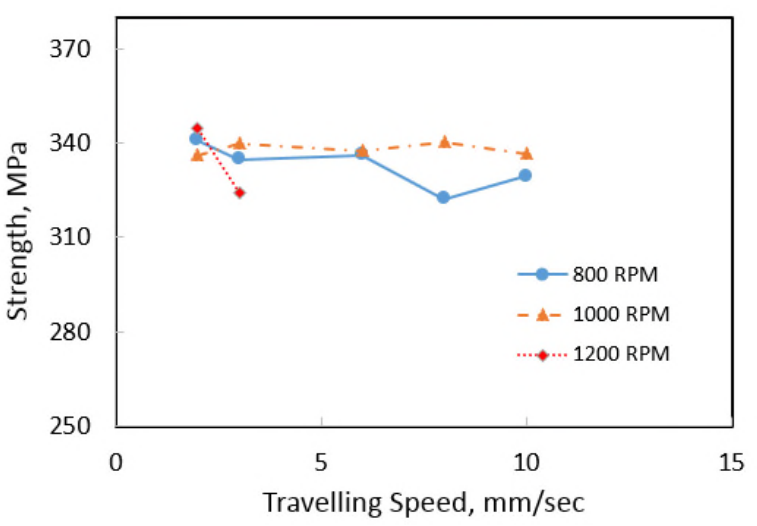

(b)

Fig. 5 Mechanical properties of welded specimen, (a) weld strength efficiency (\% relative strength to base metal, X contains defects and not tested), and (b) effect of welding parameters

\section{Summary}

The friction stir welding process was used to join aluminum alloy 2219-T87 and the optimum process condition was determined. . The process conditions include tool rotation rates from 600 to 2,000 rpm and tool traveling speeds from 0.8 to $15 \mathrm{~mm} / \mathrm{sec}$ using a tool tilt angle of $3^{\circ}$. Single pass 
welding procedure was used and no attempt was made to repair or improve the structural integrity of the joints.

The stirred zone shows sufficient deformation and heat input which cause the complete dynamic recrystallization. Specimens welded with the rotating ratio of 1,000 RPM perform well over the travelling speed range in this study by showing the weld efficiency over $70 \%$ without any defects. The maximum efficiency obtained in this study was supported with the published work. At higher rotating rate, only specimens welded at low speed were accepted in this alloy.

\section{References}

[1] R. S. Mishra, M. W. Mahoney, S. X. McFadden, N. A. Mara, and A. K. Mukherjee, High strain rate superplasticity in a friction stir processed 7075 Al Alloy, Scripta Materialia, 42 (2000) 163-168.

[2] R. S. Mishra, Z. Y. Ma, Friction stir welding and processing, Mater. Sci. Eng. R 50 (2005) 1-78.

[3] R. P. Reed, et al. Aluminum Alloys for ALS Cryogenic Tanks: Comparative Measurements of Cryogenic Mechanical Properties of Al-Li Alloys and Alloy 2219, PL-TR-91-3073, October 1991, National Institute of Standards and Technology, Boulder, CO, USA.

[4] G. Adams, P. Pareti, J. Thompson, and K. Lawless, Friction Stir Welding on the External Tank, $12^{\text {th }}$ Annual Advanced Aerospace Materials and Processes Conference, June 11-14, 2001, Los Angeles, CA, USA.

[5] J. A. Hartman, R. J. Beil, G. T. Hahn, Effects of copper rich regions on tensile properties of VPPA weldments of 2219-T87 aluminum, Welding Research Supplement, March 1987, 73-83.

[6] S. Arunkumar, P. Rangarajan, K. Devakumaran, P. Sathiya, Comparative study on transverse shrinkage, mechanical and metallurgical properties of AA2219 aluminum weld joints prepared by gas tungsten arc and gas metal arc welding processed, Defense Tech. 11 (2015) 262-268.

[7] MIL-STD-2219A, Fusion Welding for Aerospace Applications, June 16 2008, Department of Defense, USA.

[8] J. J. Muhsin, M. T. Tolephih, and A. M. Muhammed, Effect of friction stir welding parameters speed on the transient temperatures distribution in friction stir welding of AA7020-T53, Asian Res. Publ. Network J. Eng. Appl. Sci. 7 (2012) 436-446.

[9] A. J. Leonard and S. A. Lockyer, Flaws in Friction Stir Welds, $4^{\text {th }}$ International Symposium on Friction Stir Welding, May 14-16 2003, Park City, UT, USA.

[10]P. B. Srinivasan, K. S. Arora, W. Dietzel, S. Pandey, and M, K, Schaper, Characterization of microstructure, mechanical properties and corrosion behavior of an AA2219 friction stir weldment, J. Alloy. Comp. 492 (2010) 631-637. 